\title{
ISOLASI SENYAWA METABOLIT SEKUNDER STEROID DAN TERPENOID DARI 5 TANAMAN
}

\author{
Febri Nola, Gita Kurniawati Putri, Lhidya Halizah Malik, Nadia Andriani \\ Universitas Singaperbangsa Karawang (UNSIKA) Jawa Barat, Indonesia \\ Email: febbynola402@gmail.com, gitakurniawatiputri@gmail.com, \\ lhidyahalizahmalik@gmail.com, nadiaandriani33@gmail.com
}

\begin{abstract}
Abstrak
Indonesia kaya akan keanekaragaman flora dan fauna. Data menunjukkan bahwa terdapat sekitar 30.000 spesies flora di hutan tropis di Indonesia, dan sekitar 9.600 spesies tumbuhan diketahui memiliki khasiat sebagai obat. Tumbuhan menghasilkan metabolit sekunder yang memiliki sifat berracun yang dapat digunakan untuk mengobati berbagai penyakit manusia salah satunya yaitu Steroid dan Terpenoid. Beberapa tanaman yang dipakai adalah biji mahoni (Swietenia mahagonia Jacq.), rimpang temulawak (Curcuma xanthorrhiza Roxb.), herba meniran (Phyllanthus niruri Linn), buncis (Phaseolus vulgaris L.), dan batang tanaman patah tulang (Euphorbia tirucalli L.). Tujuan dari review jurnal ini yaitu untuk menganalisis isolasi senyawa metabolit sekunder steroid dan terpenoid dengan menggunakan metode studi tinjauan literatur. Isolasi senyawa steroid dan terpenoid dapat dilakukan dengan ekstraksi, fraksinasi dan bercak UV. Berdasarkan hasil pencarian literatur ini biji mahoni (Swietenia mahagonia Jacq.) mengandung steroid dan triterpenoid, rimpang temulawak (Curcuma xanthorrhiza Roxb.) mengandung seskuiterpenoid, herba meniran (Phyllanthus niruri Linn) mengandung steroid, buncis (Phaseolus vulgaris L.) mengandung steroid dan triterpenoid, dan batang tanaman patah tulang (Euphorbia tirucalli L.) mengandung steroid dan terpenoid.
\end{abstract}

Kata Kunci: isolasi senyawa; steroid; terpenoid

\section{Abstract}

Indonesia is rich in flora and fauna diversity. Data shows that there are about 30,000 species of flora in tropical forests in Indonesia, and about 9,600 species of plants are known to have medicinal properties. Plants produce secondary metabolites that have toxic properties that can be used to treat various human diseases, one of which is steroids and terpenoids. Some of the plants used are mahogany seeds (Swietenia mahagonia Jacq.), temulawak rhizomes (Curcuma xanthorrhiza Roxb.), meniran herbs (Phyllanthus niruri Linn), chickpeas (Phaseolus vulgaris L.), and broken bone stems (Euphorbia tirucalli L.). The purpose of this journal review is to analyze the isolation of steroid and terpenoid secondary metabolites by using the literature review study method. Isolation of steroid and terpenoid compounds can be done by extraction, fractionation and UV spotting. Based on the results of this literature search, mahogany seeds (Swietenia mahagonia Jacq.) contain steroids and triterpenoids, temulawak rhizomes (Curcuma xanthorrhiza Roxb.) contain sesquiterpenoids, meniran herbs (Phyllanthus niruri Linn) contain steroids, green beans (Phaseolus vulgaris L.) contain steroids and triterpenoids, and the stem of the broken bone plant (Euphorbia tirucalli L.) contains steroids and terpenoids.

\begin{tabular}{llllll}
\hline How to cite: & Febri, Nola, Gita Kurniawati Putri, Lhidya Halizah Malik, Nadia Andriani (2021) Isolasi Senyawa \\
& Metabolit Sekunder Steroid dan Terpenoid Dari 5 Tanaman, Syntax Idea $3(7)$. \\
& https://doi.org/10.36418/syntax-idea.v3i7.1307 & & & \\
E-ISSN: & 2684-883X & Ridwan Institute
\end{tabular}


Keywords: isolation coumounds; steroids; terpenoid

\section{Pendahuluan}

Indonesia kaya akan keanekaragaman flora dan fauna. Sumber keanekaragaman hayati di Indonesia memegang peranan penting di semua masyarakat. Sebagai negara dengan budaya yang kental akan pemanfaatan berbagai tanaman tradisional digunakan untuk mengobati berbagai penyakit, masyarakat terutama di pedesaan cenderung menggunakan tanaman sebagai obat tradisional untuk mengobati penyakit (Baud et al., 2014). Data menunjukkan bahwa terdapat sekitar 30.000 spesies flora di hutan tropis di Indonesia, dan sekitar 9.600 jenis tanaman diketahui memiliki manfaat sebagai obat

Perkembangan obat herbal terus dilakukan melalui pemanfaatan metabolit sekunder yang sangat potensial untuk dikembangkan menjadi obat. Masyarakat yang suka menggunakan bahan-bahan alami juga mendukung hal tersebut, karena efek sampingnya lebih rendah dibandingkan obat sintetik (Dewi, 2018). Tumbuhan menghasilkan metabolit sekunder yang bersifat racun yang dapat digunakan untuk mengobati berbagai penyakit manusia. Metabolit sekundernya adalah flavonoid, alkaloid, saponin, tanin, steroid,triterpenoid dan terpenoid. Pada review jurnal ini akan membahas salah satu metabolit sekunder yaitu steroid dan terpenoid.

Terpenoid adalah turunan terdehidrogenasi dan teroksidasi dari senyawa terpen. Terpen adalah kelompok hidrokarbon, terutama diproduksi oleh tumbuhan dan beberapa hewan seperti serangga. Rumus molekul terpena adalah (C5H8)n. Terpenoid disebut juga isoprenoid. Hal ini karena kerangka karbonnya sama dengan senyawa isoprena. Secara kimia, terpenoid adalah campuran unit isoprena, yang dapat berupa rantai terbuka atau siklik, dan dapat mengandung ikatan rangkap, gugus hidroksil, gugus karbonil, atau gugus fungsional lainnya. Adapun turunan dari senyawa terpenoid yaitu triterpenoid. Triterpenoid merupakan kerangka karbon yang berasal dari enam satuan isoprene (2 - metilbuta-1,3-diene) satuan $\mathrm{C}_{5}$ dan diturunkan dari hidrokarbon $\mathrm{C}_{30}$ asiklik, yakni skualena. Senyawa golongan triterpenoid menunjukan aktivitas farmakologi yang signifikan, seperti antiviral, antibakteri, antiinflamasi yang sebagai inhibisi sintesis kolestrol dan sebagai antikanker (Balafif et al., 2013).

Steroid adalah golongan triterpenoid yang mengandung inti siklopentana perhidrofenantrena, yang terdiri dari tiga cincin sikloheksana dan satu cincin siklopentana. Steroid memainkan peran penting dalam menjaga keseimbangan garam, mengendalikan metabolisme dan meningkatkan fungsi organ seksual dan perbedaan fungsi biologis lainnya antara jenis kelamin. Steroid pada tanaman telah menunjukkan efek penurun kolesterol dan anti kanker (Nasrudin, 2017).

Berbagai macam tumbuhan obat diduga mengandung senyawa metabolit seperti terpenoid dan steroid. Penelitian yang dilakukan (Musfiroh et al., 2011) Isolat Rimpang Temulawak (Curcuma Xanthorrhiza Roxb) yang mengandung terpenoid. Selain Curcuma Xanthorrhiza Roxb, Ekstrak Biji Mahoni (Swietenia mahagoni Jacq) mengandung steroid berdasarkan penelitian yang dilakukan oleh (Maryam et al., 2020). Tumbuhan obat lain yang juga mengandung terpenoid dan steroid adalah Ekstrak Herba Meniran (Phyllanthus niruri Linn) sesuai dengan hasil penelitian (Rivai et al., 2017) dan Batang Tanaman patah tulang (Euphorbia tirucalli L) pada hasil penelitian (Baud et al., 2014). Sedangkan kelompok 
terpenoid lainnya yaitu Buah buncis (Phaseolus vulgaris L) pada penelitian (R Nugrahani, 2015). Tujuan dari mereview jurnal ini yaitu untuk mengumpulkan dan menganalisis isolasi senyawa metabolit sekunder steroid, terpenoid dan triterpenoid dari beberapa jenis tanaman.

\section{Metode Penelitian}

Review jurnal ini dilakukan dengan metode mencari berbagai jurnal penelitian ilmiah berbahasa Indonesia yang berkaitan dengan isolasi metabolit sekunder dari tanaman yang mengandung steroid dan terpenoid. Sumber tinjauan literatur ini meliputi studi pencarian sistematis informasi jurnal berupa google cendikia dengan 15 jurnal yang direview.

\section{Hasil dan Pembahasan}

\section{A. Hasil Penelitian}

\begin{tabular}{|c|c|c|}
\hline Sample & Hasil & Keterangan \\
\hline \multirow[t]{2}{*}{$\begin{array}{l}\text { Biji mahoni (Swietenia } \\
\text { mahagoni Jacq.) }\end{array}$} & $\begin{array}{l}\text { Terbentuk cincin merah } \\
\text { kecoklatan, lapisan atas } \\
\text { berwarna ungu atau } \\
\text { bening dan lapisan } \\
\text { bawah berwarna merah }\end{array}$ & (+) Triterpenoid \\
\hline & $\begin{array}{l}\text { Terbentuk cincin coklat } \\
\text { kemerahan }\end{array}$ & (+) Steroid \\
\hline $\begin{array}{l}\text { Rimpang Temulawak } \\
\text { (Curcuma xanthorrhiza } \\
\text { Roxb.) }\end{array}$ & $\begin{array}{l}\text { Terbentuk cairan seperti } \\
\text { minyak, } \\
\text { kuning }\end{array}$ & (+) Seskuiterpenoid \\
\hline \multirow{2}{*}{$\begin{array}{l}\text { Herba Meniran } \\
\text { (Phyllanthus niruri Linn) }\end{array}$} & $\begin{array}{l}\text { Muncul warna coklat } \\
\text { kemerahan }\end{array}$ & (+) Steroid \\
\hline & $\begin{array}{l}\text { Muncul warna merah } \\
\text { muda }\end{array}$ & (+) Terpenoid \\
\hline \multirow[t]{2}{*}{$\begin{array}{l}\text { Buah Buncis (Phaseolus } \\
\text { vulgaris } L \text { ) }\end{array}$} & \begin{tabular}{lr} 
Cincin & \multicolumn{2}{c}{ berwarna } \\
kecoklatan & pada batas \\
dua pelarut &
\end{tabular} & (+) Triterpenoid \\
\hline & Menjadi warna hijau & (+) Steroid \\
\hline \multirow{2}{*}{$\begin{array}{l}\text { batang tanaman patah } \\
\text { tulang (Euphorbia tirucalli } \\
\text { L.) }\end{array}$} & $\begin{array}{l}\text { Berwarna merah atau } \\
\text { ungu }\end{array}$ & (+) Terpenoid \\
\hline & Berwarna biru atau hijau & (+) Steroid \\
\hline
\end{tabular}

\section{B. Pembahasan}

Tumbuhan menghasilkan metabolit sekunder yang bersifat racun yang dapat digunakan untuk mengobati berbagai penyakit manusia. Metabolit sekunder tersebut berupa Steroid, Triterpenoid dan Terpenoid. Berbagai macam tumbuhan obat diduga mengandung senyawa metabolit seperti terpenoid dan steroid.

Tanaman yang diduga mengandung steroid adalah biji mahoni (Swietenia mahagonia Jacq.) . Mahoni (Swietenia mahagonia Jacq.) merupakan family Meliaceae, yang dapat tumbuh di daerah tropis benua Asia. Biji mahoni ditemukan sebagai vitamin 
dan obat-obatan, di Indonesia itu sendiri mahoni dimanfaatkan sebagai obat Diabetes Melitus (Ambarwati \& Theresih, 2018).

Pada awalnya terbukti menggunakan metode maserasi bertingkat berdasarkan 3 pelarut dengan tingkat kepolaran mulai dari yang paling non-polar sampai yang paling polar yaitu heksana, etil asetat dan etanol. Ekstrak yang diperoleh selanjutnya dilakukan skrining fitokimia untuk mengetahui kandungan senyawa steroid dari ektrak biji mahoni (Swetenia mahagoni Jacq.). Kemudian berdasarkan uji skrining fitokimia beberapa ekstrak biji mahoni, menunjukan adanya senyawa stroid dalam ekstrak etil asetat. Hal ini didukung oleh penelitian bahwa dibandingkan dengan pelarut n-heksan dan methanol, penggunaan pelarut etil asetat dalam ekstraksi dapat menghasilkan rendemen yang paling tinggi dan efektif menarik senyawa Steroid. Selanjutnya digunakan fase diam silica gel G60 dan fase gerak n-heksan : etil asetat untuk memisahkan 5 gram ektrak biji mahoni dengan Kromatografi kolom. Fase gerak tersebut telah diuji kelarutannya sebelumnya, dari kepolaran rendah hingga kepolaran tinggi. Kromatografi Kolom adalah metode yang sangat baik untuk memisahkan sejumlah kecil komponen kimia dan memperoleh hasil dengan cepat. Menurut distribusi nilai Rf dan cara pemisahan hasil kromatografi KLT, diperoleh total 6 fraksi gabungan dari 70 vial. Hasil isolasi dan karakterisasi senyawa steroid dari ekstrak etil asetat biji mahoni diperoleh isolate P2b yang diduga merupakan senyawa steroid, dan uji gugus senyawa pada ekstrak menunjukan hasil positif mengandung steroid (Maryam \& Musthainah, 2020).

Tanaman kedua yaitu pada rimpang temulawak (Curcuma xanthorrhiza Roxb.). Temulawak itu sendiri banyak dimanfaatkan oleh masyarakat sebagai bahan pangan, pewarna serta obat tradisional atau bahan obat diakarenakan temulawak dapat memelihara kesehatan serta dapat mengobati seseorang yang kurang nafsu makan, sembelit/ambeien, jerawat, obat kejang - kejang , diare dan sebagainya (Aldizal et al., 2019). Temulawak pun terdiri dari beberapa metabolit baik primer maupun sekunder, salah satunya yaitu steroid. Cara membuktikan adanya senyawa metabolit sekunder yaitu dengan melakukan identifikasi isolasi senyawa. Sebagai hasil ekstraksi dan fraksinasi, diperoleh 0,902 g (rendemen 15,18\%) untuk ekstrak methanol pekat dan 0,308 g (rendemen 34,02\%) fraksi etil asetat. Fraksi etil Asetat diisolasi menggunakan Kromatografi Cair Vakum (KCV) dengan Fase gerak $\mathrm{n}$ - heksan dan etil asetat secara bertahap meningkat polaritasnya dan fase diam silika gel $60 \mathrm{H}$. Dari hasil KLT Didapatkan lima kelompok fraksi, yaitu fraksi A, B, C, dan E, diperoleh dari profil KLT dengan plat silica gel GF254, pelarut toluene etil asetat (93:7), dan penampak bercak vanillin sulfat 10\%. Kemudian fraksi A membentuk cairan berwarna kekuningan seperti minyak dan terdiri dari dua bercak. Lalu fraksi A disaring menggunakan metode KLT preparatif dengan mengembangkan toluene etil asetat (99:1) serta didapatkan isolate dari penampak bercak vanillin sulfat yang disebut CXA, dan menghasilkan $10 \%$ vanillin sulfat digunakan untuk deteksi, nilai Rf adalah titik tunggal 0,85. Kemurnian isolat dilakukan dengan KLT dua dimensi menggunakan dua sistem pengembangan yang berbeda. Pengembang pertama adalah toluena-etil asetat (99:1) dan yang kedua adalah n-heksana-etil asetat (6:4). Bintik yang dihasilkan adalah noda tunggal saat diuji dengan nilon sulfat $10 \%$. Isolat CXA diduga merupakan seskuiterpenoid karena menghasilkan warna ketika sampel diekstraksi dengan eter dan diteteskan ke dalam larutan vanillin sulfat (Musfiroh et al., 2011). Adapun penelitian lain 
menyebutkan bahwa rimpang temulawak mengandung senyawa steroid yang berupa diantaranya estrogen yang digunkan untuk mencegah keguguran dan uji kehamilan (Agustina et al., 2016).

Tanaman selanjutnya yaitu herba meniran (Phyllanthus niruri Linn). Langkah pertana yaitu herba meniran yang masih segar, kemudian dikeringkan dan dihaluskan untuk memperoleh ekstrak herba meniran. Langkah pertama yang dilakukan untuk membuktikan dengan isolasi senyawa, estrak herba meniran diperoleh dari herba meniran segar yang telah dikeringkan dan dihaluskan, kemudian sampel direndam dalam methanol 96\% selama 6 jam untuk dimaserasi dan dipekatkan dengan dengan rotary evaporator. Didapatkan hasil ekstraksi 40 gr ekstrak pekat. Pada langkah kedua dilakukan fraksinasi dengan cara ekstrak herba meniran ditimbang sebanyak 14 gr, dilarutkan dalam lumpang dengan aquadest, gerus perlahan, pindahkan ekstrak terlarut ke corong pisah $100 \mathrm{ml}$, kocok kuat-kuat untuk melarutkan ekstrak. selanjutnya eter dan air ditambahkan secukupnya, kocok kuat-kuat selama \pm 15 menit lalu biarkan sampai membentuk 2 lapisan. Lapisan yang palih bawah berupa air dipindahkan perlahan-lahan ke dalam Erlenmeyer melalui keran dibagian bawah corong pemisah. Setelah hasil fraksinasi, dilakukan uji skrining fitokimia untuk mengetahui metabolit sekunder steroid. Pada pengujian ini dilakukan uji salkowiski, dengan hati-hati $0,5 \mathrm{ml}$ ekstrak kloroform dan $1 \mathrm{ml}$ asam sulfat pekat ditambahkan kedalam tabung reaksi, kemudian muncul warna coklat kemerahan, menandakan bahwa ekstrak meniran positif mengandung steroid (Rivai et al., 2017). Sedangkan apabila hasil isolasi berubah warna menjadi warna merah muda dengan menggunakan pereaksi Lieberman Burchard, hal tersebut menandakan bahwa isolate mengandung senyawa golongan terpenoid (Risnawati et al., 2021).

Tanaman yang mengandung terpenoid adalah buncis (Phaseolus vulgaris L.). Rendam buncis segar dengan air sebagai pelarut, panaskan dan keringkan pada suhu tinggi setelah diserbukkan untuk dijadikan sampel, masukkan sampel ke dalam botol plastik kedap udara, kemudian ubah suhu penyimpanan yang telah ditentukan yaitu kurang dari 1 bulan mencapai \pm 3 bulan pada suhu ruang. Untuk uji skrining fitokimia dilakukan dengan melarutkan 0,1 g sampel dalam methanol kemudian diuapkan di atas penangas air. Setelah filtrate dihaluskan, larutkan dalam tabung reaksi dengan $2 \mathrm{~mL}$ kloroform, tambahkan 10 tetes asetat anhidrada, lalu tambahkan \pm 3 tetes $\mathrm{H}_{2} \mathrm{SO}_{4}$ pekat melalui dinding tabung reaksi. Tambahkan sampel larutan anhidrida asetat dan asam sulfat pekat menunjukkan hasil positif mengandung senyawa triterpenoid berupa perubahan warna cincin coklat pada batas kedua pelarut dan mengandung senyawa steroid berupa perubahan warna menjadi hijau yang terjadi karena mengembun atau melepaskan $\mathrm{H}_{2} \mathrm{O}$ dan bergabung dengan Karbokation (Rizki Nugrahani et al., 2016). Berdasarkan penelitian sebelumnya tanaman buncis menggunakan ekstrak kental diketahui tanaman buncis mengandung komponen senyawa kimia (Balafif et al., 2013)

Tanaman lain yang diduga memiliki senyawa steroid dan triterpenoid adalah batang tanaman patah tulang (Euphorbia tirucalli L.) dengan tahapan awal proses pembuatan simplisia dengan tanaman patah tulang dipisahkan dari kotoran - kotoran yang menempel, kemudian dicuci hingga bersih dan tiriskan. Selanjutnya tempatkan tanaman yang sudah bersih di atas nampan untuk dikeringkan dibawah sinar matahari ataupun di masukkan ke dalam oven dengan suhu $50^{\circ} \mathrm{C}$. Setelah kering tanaman patah tulang dihaluskan 
menggunakan blender hingga menjadi serbuk halus (Wahid, 2019). Proses kedua yaitu ekstraksi batang tanaman patah tulang dilakukan dengan menggunakan metode maserasi. Perendaman $100 \mathrm{~g}$ sampel yang telah dihaluskan dalam $500 \mathrm{~mL}$ etanol $96 \%$ p.a selama 2x24 jam sambil sesekali dikocok, kemudian saring, dan rendam kembali residu dengan $250 \mathrm{~mL}$ etanol $96 \%$ p.a, kemudian kocok dan simpan selama $2 \times 24$ jam, lalu saring. Filtrat yang diperoleh dari perendaman pertama dan kedua dicampur dan diuapkan, kemudian dimasukkan ke dalam oven pada suhu $40-500^{\circ} \mathrm{C}$ untuk mendapatkan ekstrak kental. Uji skrinning fitokimia dilakukan dengan penambahan $\mathrm{CH}_{3} \mathrm{COOH}$ glasial sebanyak 10 tetes dan $\mathrm{H}_{2} \mathrm{SO}_{4}$ pekat sebanyak 2 tetes ke dalam sejumlah sampel. Sampel yang telah ditambahkan $\mathrm{CH}_{3} \mathrm{COOH}$ glasial dan $\mathrm{H}_{2} \mathrm{SO}_{4}$ pekat menunjukan kedua ekstrak etanol batang tanaman patah tulang menunjukkan hasil positif mengandung senyawa triterpenoid membentuk warna merah atau ungu dan untuk senyawa steroid membentuk warna biru atau hijau. Warna hijau yang terbentuk disebabkan oleh reaksi ekstrak etanol batang tanaman Patah tulang dengan asam $\left(\mathrm{CH}_{3} \mathrm{COOH}\right.$ glasial dan $\mathrm{H}_{2} \mathrm{SO}_{4}$ pekat) (Baud et al., 2014).

\section{Kesimpulan}

Hasil dari pencarian dari beberapa literatur ini dapat disimpulkan bahwa, biji mahoni (Swietenia mahagonia Jacq.) mengandung steroid dan triterpenoid, rimpang temulawak (Curcuma xanthorrhiza Roxb.) mengandung seskuiterpenoid, herba meniran (Phyllanthus niruri Linn) mengandung steroid, buncis (Phaseolus vulgaris L.) mengandung steroid dan triterpenoid, dan batang tanaman patah tulang (Euphorbia tirucalli L.) mengandung steroid dan terpenoid. 
Febri Nola, Gita Kurniawati Putri, Lhidya Halizah Malik, Nadia Andriani

\section{BIBLIOGRAFI}

Agustina, S., Wiraningtyas, A., \& Bima, K. (2016). Skrining fitokimia tanaman obat di kabupaten bima. 4, 71-76. Google Scholar

Aldizal, R., Rizkio, M., Perdana, F., Suci, F., Galuh, V., Putri, A., Rina, A., Cahyani, N. D., Yanti, R., Khendri, F., Garut, F. M., \& No, J. J. (2019). Jurnal Ilmiah Farmako Bahari Temulawak Plant ( Curcuma Xanthorrhiza Roxb) As A Traditional Medicine Review: Tanaman Temulawak ( Curcuma Xanthorrhiza Roxb ) Sebagai Obat Tradisional. 51-65. Google Scholar

Ambarwati, O., \& Theresih, K. (2018). Isolasi Dan Identifikasi Senyawa Metabolit Sekunder Dari Biji Mahoni ( Swietenia Mahagoni Jacq .) Menggunakan Metode Ekstraksi Soxhlet Pelarut Etanol Isolation And Identification Of Secondary Metabolite Compounds From. Kimia Dasar,7(3), 88-95. Google Scholar

Balafif, R. A. R., Andayani, Y., \& Gunawan, R. (2013). Analisis Senyawa Triterpenoid Dari Hasil Fraksinasi Ekstrak Air Buah Buncis ( Phaseolus Vulgaris Linn ). 6(2), 56-61. Google Scholar

Baud, G. S., Sangi, M. S., \& Koleangan, H. S. J. (2014). Analisis senyawa metabolit sekunder dan uji toksisitas ekstrak etanol batang tanaman patah tulang (Euphorbia tirucalli L.) dengan metode Brine Shrimp Lethality Test (BSLT). Jurnal Ilmiah Sains, 14(2), 106-112. Google Scholar

Dewi, N. L. A. (2018). Pemisahan, Isolasi, dan Identifikasi Senyawa Saponin Dari Herba Pegagan (Centella asiatica L. Urban). Jurnal Farmasi Udayana, 7(2), 68. Google Scholar

Maryam, F., \& Musthainah, L. (2020). Isolasi Dan Karakterisasi Senyawa Steroid Dari Ekstrak Biji Mahoni ( Swietenia mahagoni Jacq .). 7(2), 6-11. Google Scholar

Maryam, F., Subehan, S., \& Musthainah, L. (2020). Isolasi Dan Karakterisasi Senyawa Steroid Dari Ekstrak Biji Mahoni (Swietenia mahagoni Jacq.). Jurnal Fitofarmaka Indonesia, 7(2), 6-11. Google Scholar

Musfiroh, I., Diantini, A., Levita, J., \& Mustarichie, R. (2011). Aktivitas Antiproliferasi Ekstrak, Fraksi Etil Asetat Dan Isolat Rimpang Temulawak (Curcuma Xanthorrhiza Roxb.) Terhadap Sel Kanker Payudara T47d. Bionatura, 13(2). Google Scholar

Nasrudin, N. (2017). Isolasi Senyawa Steroid Dari Kukit Akar Senggugu (Clerodendrum Serratum L. Moon). Pharmacon, 6(3). Google Scholar

Nugrahani, R. (2015). Analisis Potensi Serbuk Ekstrak Buncis (Phaseolus vulgaris L.) sebagai Antioksidan. Tesis S2. Universitas Mataram. Google Scholar

Nugrahani, Rizki, Andayani, Y., Pascasarjana, P., Mataram, U., \& Words, K. (2016). Jurnal penelitian pendidikan ipa. Google Scholar

Risnawati, R., Muharram, M., \& Jusniar, J. (2021). Isolasi dan Identifikasi Senyawa 
Metabolit Sekunder Ekstrak n-heksana Tumbuhan Meniran (Phyllanthus niruri Linn.). Chemica: Jurnal Ilmiah Kimia Dan Pendidikan Kimia, 22(1), 65-73. Google Scholar

Rivai, H., Septika, R., \& Boestari, A. (2017). Karakterisasi ekstrak herba meniran (Phyllanthus niruri Linn) dengan analisa Rivai, Harrizul, Septika, Refilia, \& Boestari, Agusri. (2017). Karakterisasi ekstrak herba meniran (Phyllanthus niruri Linn) dengan analisa fluoresensi. Jurnal Farmasi Higea, 5(2. Jurnal Farmasi Higea, 5(2), 127-136. Google Scholar

Wahid, A. R. (2019). Skrining Fitokimia Senyawa Metabolit Sekunder Terhadap Ekstrak Tanaman Ranting Patah Tulang ( Euphorbia Tirucalli L .). 23(1), 45-47. Google Scholar

$$
\text { Copyright holder : }
$$

Febri Nola, Gita Kurniawati Putri, Lhidya Halizah Malik, Nadia Andriani (2021)

\section{First publication right :}

Syntax Idea

This article is licensed under:

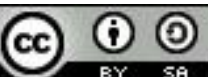

